\title{
PRESENTATION OF THE 1965 ARTHUR L. DAY MEDAL TO WALTER H. MUNK
}

\section{Citation by Frank Press}

\section{Mr. President, Ladies and Gentlemen:}

I was asked last night "Who is Walter Munk?". Walter Munk has never published in our Bulletin. This may be the first meeting of our Society he has attended. His membership I believe, begins today. Yet Arthur L. Day would have been pleased with the selection of Walter Munk as the 1965 Day Medalist -and for good reason. Walter Munk's interests and contributions range from oceanography to the mechanical properties of the earth. He brings a fresh point of view to classic problems and opens new fields. His approach varies with the subject. It is experimental when new data are needed; Munk will not hesitate to conceive and build in his own laboratory, as he is now doing, a mid-ocean tide gage, displacement meters, strain and tiltmeters, to measure tectonic movements. His approach is also theoretical and numerical when data remain to be analyzed or explained. Munk was among the first in the earth sciences to exploit high speed electronic computers. His early work in geophysical time series applied to the study of long

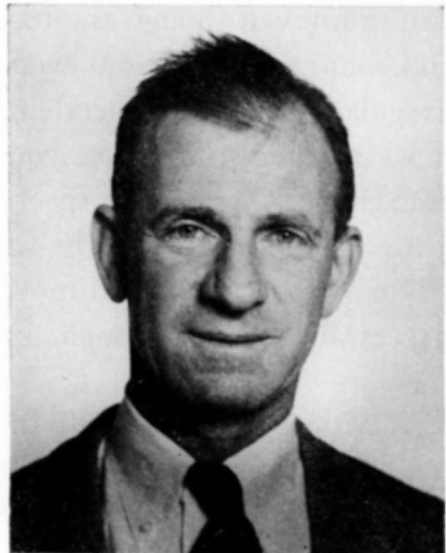

Walter Munk, 1965 Recipient of the Arthur L. Day Medal sea waves and resonant vibrations of the earth presaged major developments in this field.

Munk's study of the earth's rotation, its wobble, its perturbations, updates a subject that has lain dormant for some fifty years. The implications regarding the evolution of the core and motions in the core are many. His studies of pole movements combine, for the first time, the methods of the physicists and the data of the geologist.

So much for the accomplishments, incompletely described. What about the man? His taste and style may be judged from the way he has built a new geophysical institute at the University of California in La Jolla-a warm, redwood building, architecturally unique for laboratories, overlooking the Pacific Ocean, a bright blue rug, all offices with ocean views, artistic sculpture and paintings. He has gathered a group of physicists, mathematicians, oceanographers, seismologists - even astronomers - to tackle the nonroutine problems. This group shuns the dull and uninteresting like the plague! It tackles the novel, the off-beat, and always the significant problem.

Judge the man another way-by his aphorisms which have now become famous:

The oceans do not yield up their secrets to brute force.

Low frequency seismology - high frequency geology.

"Afterglow" for tsunami reverberation. 
In his scientific work and personal relationships, Walter is a man of charm, wit, and grace. It is a pleasure to present him to you, Mr. President.

\section{Response by Walter H. Munk}

\section{Mr. President, Ladies and Gentlemen:}

On many previous occasions of this award, the recipients would give some vital reasons why they had chosen for their career the study of the Earth. I wish I could. When I was a graduate student at Cal Tech, I fell in love with a girl from La Jolla, and the only way I could see something of her was to take a summer job at the Scripps Institution of Oceanography. The girls have changed, but I have never moved.

A fascination for ocean waves arose from a war-time need to predict sea and swell for amphibious landings. Why is it that ocean waves are so fascinating to people? I think it is because they are moderately confused. Pure sine waves are predictable from wave to wave and really quite dull. Highly chaotic processes are unpredictable and disturbing. Ocean waves fall nicely between these extremes; their pattern is ever changing, yet an experienced surfer can anticipate a good breaker one or two waves in advance. In 1940 no one knew how to give a quantitative description of waves which included their irregularity as part of the description (even though the tools were available through previous work on optical and sonic spectra). Now everyone does, and there has been substantial progress. Irregularity and unpredictability increase with spectral band width, from zero band width (line spectra) for complete predictability, to a "white noise" at the other extreme. Ocean wave spectra are typically an octave wide, which seems to be a nice compromise. In the application of wave research to geological processes, to beach erosion and sand movements, it has not been possible so far to carry these spectral concepts through, and I became interested in simpler problems.

One way to study the planet Earth is to observe irregularities in its rotation. In this manner one can learn about the growth of the core, the variable distribution of glaciation, air mass, global winds, bulk visocity, etc. In each case the information is related to certain integral quantities (moments) taken over the entire globe. This is the weakness of the method-and its strength. For some reason the subject has attracted a larger than the usual share of crackpots; nowhere is the line more thinly drawn than between your imaginative work and the irresponsible scheme of other people.

The astronomers were the first to attempt to exploit, for geological purposes, the irregularities they had discovered. They did this in the naive faith that the simplicity of celestial mechanics can be carried over to messy objects like the Earth. And so they applied their astronomic jargon and spoke of the "proper motion" of observatories, and they suddenly raised the Himalayan complex by one foot. There was a curious dichotomy between those who measured latitude and so inferred the wobble of the Earth relative to a rotation axis fixed in space, and those who com- 
pared Siderial Time to Ephemeral Time (later to Atomic Time) and thus inferred the variable spin. But wobble and spin are the three components of one vector, and for geophysical processes the observations of latitude and time had better be discussed together. Here were wonderful opportunities for learning new things about the planet Earth.

Both wobble and spin have now developed a paleo aspect. Low frequency wobble (or polar wandering) can be inferred from palaeomagnetism. At the time I became interested in the subject I tried in vain to think of some possible methods for determining the past length-of-day. Now John Wells has hit upon the ingenious realization that ancient corals show tiny striations that can be identified with a differential uptake of carbonate between night and day; the corals also show modulations of these markings which he attributes to the variation between summer and winter. The number of striations per annulation gives the number of days per year. He finds the Devonian year had 405 Devonian days, and since the year has remained sensibly constant this gives a Devonian length-of-day of 22 hours. Scrutton at Oxford has been able to count the number of striations per lunation, and so derive the paleo length-of-month. Together these measurements permit in principle the separation of the slowing down in rotation by tidal friction, and the speeding up, if any, by differentiation (settling of the core, etc.). Perhaps we can end up with a quantitative measure (instead of the usual arm waving) of progressive differentiation during the last 500 million years.

Recently Frank Press has reported a permanent change in strain at Hawaii by $10^{-8}$ as a consequence of the Alaskan Good Friday earthquake, and this implies a relative movement between the two places by a centimeter. The rate of strain in California and Alaska is typically $10^{-6}$ per year. If an instrument can measure strain to $10^{-5}$, then you need to wait 10 years for a result; if it can be improved to a precision of $10^{-7}$, then you may hope for monthly readings. From the point of view of a Ph.D. student the improvement is of consequence. Instruments for measuring the strain field to $10^{-7}$ are becoming available; strain seismographs, gravimeters, tiltmeters, jerkmeters, etc. The difficulty is to achieve low noise level at very low frequencies.

We have here the possibility of measuring in real time the rise of the Sierras, the splitting of the Gulf of California, perhaps even a separation of continents if this consists of an accumulation of small abrupt "jerks" (call it continental drift, if you wish). The unique opportunity arises from the joining of two fields: ULF seismology and UHF geology. How little would we know of the oceans if we had never measured a current, of the atmosphere if we had never observed a wind. But this is the situation in geology where we have never really measured the motion of the crust; what has been done is equivalent to the measurement of currents by drift bottles whose time and place of release is not given in advance.

Here you are-having a nongeologist holding forth on geological problems. It is a credit to your tolerance that you have not resented this intrusion - that you have encouraged it with the award of this coveted medal. 